\title{
MEASURING "THE SOCIAL EVIL": THE INCIDENCE OF VENEREAL DISEASE IN INTERWAR SCOTLAND
}

\author{
by
}

\author{
ROGER DAVIDSON *
}

\section{THE CONTEXT}

The celebrated conclusion of the Royal Commission on Venereal Diseases in 1916 that "the number of persons ... infected with syphilis, acquired or congenital, cannot fall below 10 per cent of the whole population in the large cities, and the percentage affected by gonorrhoea must greatly exceed this proportion"1 continued to inform the social politics surrounding the administration of sexually transmitted diseases in Scotland for much of the interwar period. It fuelled contemporary crisis perceptions of the incidence of the "social evil" and of its implications for the health, efficiency, and social morality of the nation, and continued to be quoted by Scottish public health administrators well into the 1920s. ${ }^{2}$ In the Scottish popular and medical press, in the proceedings of Scottish local authorities and the Convention of Royal Burghs, and in the representations of medico-moral pressure groups operating north of the Border, VD remained for many years a menacing "scourge" and "hidden plague" sapping the vitality of the race. ${ }^{3}$

Similar perceptions served in part to underpin the sustained campaign in interwar Scotland for more stringent local authority powers to combat the spread of venereal disease, including the introduction of compulsory notification and/or compulsory treatment for those infected. ${ }^{4}$ Armed with the rhetoric of "national efficiency" and

* Roger Davidson, Ph.D., F.R.Hist.S., Senior Lecturer in Economic and Social History, University of Edinburgh, 50 George Square, Edinburgh EH8 9JY.

I am indebted to Dr Michael Barfoot, Archivist of Lothian Health Board's Medical Archive Centre, for his generous advice on primary sources, and to Dr A. McMillan, Consultant Physician, Department of Genito-Urinary Medicine, Royal Infirmary of Edinburgh, for his comments on an earlier draft of this paper.

' Final report of the Royal Commission on venereal diseases, P[arl.] P[apers] 1916 (Cd. 8189) XVI, p. 23.

${ }^{2}$ See, e.g., Glasgow Medical Officer of Health, annual reports, 1914-1919, p. 93; Br. med. J., 1922, i: 778; Glasgow Herald, 16 Jan. 1922, p. 5; Aberdeen M.O.H., annual report, 1924, p. 26. Acute concern over the incidence of post-war VD was also a feature of public debate in many other countries. See, for example, A. M. Brandt, No magic bullet: a social history of venereal disease in the United States since 1880, Oxford University Press, 1985, ch. 4; C. Quétel, History of syphilis, Cambridge, Polity Press, 1990, pp. 199-202; P. Fleming, 'Fighting the "Red Plague": observations on the response to venereal disease in New Zealand 1910-45', N. Z. J. Hist., 1988, 22: 56-64.

${ }^{3}$ See, e.g., Glasgow Herald, 12 Sept. 1921, p. 7; 9 Sept. 1922, p. 7; 14 Dec. 1922, p. 2; 9 March 1923, p. 6; T. F. Dewar, 'On the incidence of venereal disease in Scotland', Edinburgh Med. J., 1923, 30: 335; S[cottish] R[ecord] O[ffice], HH 65/115, Venereal Disease Legislation: Representations by Local Authorities.

${ }^{4}$ For a detailed account of this campaign, see Roger Davidson, "“A scourge to be firmly gripped": the campaign for VD controls in interwar Scotland', Soc. Hist. Med., (forthcoming, 1993). 


\section{Roger Davidson}

"social hygiene", the backing of all the major local authorities and the support of a wide range of professional groups within Scottish society including clinicians, Medical Officers of Health and medical experts within the Scottish Board of Health, this campaign for controls both exploited and reinforced existing assumptions about the widespread incidence of venereal diseases within the community. ${ }^{5}$

Yet, after 1923, there was little effort on the part of social commentators and medical officials in Scotland to test these assumptions. For the most part, a defeatist attitude to quantifying the problem prevailed. Thus, in the early 1920s, the Scottish Board of Health were at pains to stress that "no reliable measure existed of the level of venereal diseases within the community" and that estimates of their incidence in Scotland had "to be founded largely upon conjecture". 6 Similarly, as late as 1934, the Scottish Department of Health endorsed the consensus view of Scottish venereologists that, in the absence of any system of compulsory notification, the level of infection in the country remained "unknown". 7 Very occasionally, Medical Officers of Health were prepared to speculate tentatively about trends in the incidence and severity of syphilis or gonorrhoea at the local level but they were either unwilling or unable to quantify their impressions.

Moreover, with rare exceptions, ${ }^{8}$ social and medical historians of modern Britain have continued to evade the issue of how far contemporary crisis perceptions of venereal disease were justified. Partly as a response to the threat of AIDS, increasing attention has focused upon the implications of early twentieth-century venereal disease for State intervention and the regulation of sexuality, ${ }^{9}$ but little attempt has been made to measure the magnitude of the "social evil" within interwar society, despite the wide-ranging contemporary claims of its impact, not only upon levels of mortality and morbidity, but also upon industrial efficiency and the quality of family life.

This article seeks to rectify this omission for Scotland by examining a range of data located in the public archives, in the annual reports of public health authorities, and in the medical literature of the period. In so doing, it is hoped to provide a firmer base for locating venereal disease within the social and medical history of the period. ${ }^{10}$ It will

\footnotetext{
${ }^{5}$ In an attempt to contain the spread of VD, the campaign produced a range of legislative proposals. The Venereal Disease (Children) (Scotland) Bill of 1923 proposed that all cases of congenital venereal infection be notifiable and that Medical Officers of Health be empowered to examine and test parents of infected children and to require their recourse to treatment in the interests of family and public health. The Edinburgh Corporation (Venereal Disease) Bill of 1928 advocated similar controls over anyone believed to be infected, and, as initially drafted, provided for committal to hospital and detention for treatment. The Glasgow sponsored Venereal Disease (Scotland) Bill of 1928 sought to make it a legal duty of infected persons and parents of infected children to submit to professional treatment, with provision for the notification and possible prosecution and detention of defaulters.

${ }^{6} \mathrm{Br}$. med. J., 1920, ii: 80; T. F. Dewar, op. cit., note 3 above, p. 314.

${ }^{7}$ S[cottish] D[epartment of] H[ealth], annual report, 1934, p. 86.

${ }^{8}$ See especially, J. M. Winter, 'Military Fitness and Civilian Health in Britain during the First World War', J. Contemp. Hist., 1980, 15: p. 236.

${ }^{9}$ See, e.g., Frank Mort, Dangerous sexualities: medico-moral politics in England since 1830, London, Routledge and Kegan Paul, 1987, pt. 4; R. Davenport-Hines, Sex, death and punishment: attitudes to sex and sexuality in Britain since the Renaissance, London, Fontana Press, 1991, chs. 5-7; L. Bland, "“Cleansing the portals of life": the venereal disease campaign in the early twentieth century', in M. Langan and B. Schwarz, (eds), Crises in the British state 1880-1930, London, Hutchinson, 1985, pp. 192-208.

${ }^{10}$ For an overview of Scottish society and developments in Scottish health provisions during the interwar period, see especially, T. C. Smout, A century of the Scottish people, London, Collins, 1986; D. Hamilton,
} 


\section{Venereal disease in interwar Scotland}

also serve to illuminate how far a previous moral panic surrounding sexually transmitted diseases and precipitating coercive strategies towards the afflicted was driven by a set of socio-medical assumptions rather than solid evidence as to the prevalence of infection.

\section{MORTALITY DATA}

There were three main sources of information upon which estimates of the incidence of venereal disease might have been based; the Registrar-General's mortality reports, the results of Wasserman and other reaction testing for syphilis, and the case records of the local authority VD treatment centres set up in accordance with the Public Health (Venereal Diseases) Regulations of 1916.

Several contemporary studies sought to use mortality statistics as a means of establishing the incidence of venereal disease, and specifically syphilis, within the Scottish community. ${ }^{11}$ The problems of using such data were legion. Death certification grossly understated the prevalence of syphilis. Difficulties of diagnosis, such as the tendency of secondary diseases (e.g. cerebral haemorrhage and hemiplegia) to mask the underlying syphilitic cause of death, and the widespread and natural reluctance of practitioners to certify private patients in a family practice as dying from venereal disease, rendered the returns "worthless as an absolute statement of the number of deaths". 12

However, mortality figures from tabes and general paralysis of the insane (G.P.I.) were regarded as a useful, albeit crude index of its "progress or regress". ${ }^{13}$ As these diseases were invariably caused by syphilis and were more accurately certified, trends over time could be interpreted with more confidence. As Graphs 1 and 2 reveal, statistics of interwar recorded deaths (absolute numbers and per million live population) from locomotor ataxia (tabes dorsalis) and general paralysis of the insane in Scotland did not entirely justify crisis perceptions. After 1920, there was a clear and sustained downturn in the incidence of mortality from G.P.I., with the annual level of deaths averaged for the period 1935-39 some 61 per cent down on deaths for the period 1915-19. Mortality figures for tabes are more stable, but they also decline on trend after the mid-1920s, with the five-yearly averages recording a downturn of some 28 per cent for the interwar period. ${ }^{14}$ Moreover, although the Scottish data are

The healers: a history of medicine in Scotland, Edinburgh, Canongate, 1981, ch. 7; I. Levitt, Poverty and welfare in Scotland 1890-1948, Edinburgh University Press, 1988, ch. 7; G. McLachlan (ed.), Improving the common weal: aspects of Scottish health services 1900-1984, Edinburgh University Press, 1987.

"' See especially, F. Dittmar, 'The prevalence of venereal diseases in Scotland', Transactions of the Incorporated Sanitary Association of Scotland, 1919, pp. 45-55; Dewar, op. cit., note 3 above, pp. 316-21; D. White, 'Thoughts on the prevalence of syphilis', Br. J. Venereal Dis., 1925, 1: pp, 136-45.

${ }^{12}$ See R.C. on venereal diseases, op. cit., note 1 above, p. 6; minutes of evidence of $\mathrm{Dr} J$. C. Dunlop, Superintendent of Statistics, Office of Registrar General for Scotland; P.P. 1914 (Cd 7475) XLIX, qq. 1325-1592. As one medical correspondent admitted: "The general practitioner whose honesty was such as to compel him to insert the word 'syphilitic' in front of 'cerebral haemorrhage'... would very soon find himself minus a practice", Br. med. J., 1920, ii: 257.

${ }^{13}$ See, White, op. cit., note 11 above, p. 139; Dewar, op. cit., note 3 above, p. 319.

${ }^{14}$ Registrar-General for Scotland, annual reports, see especially, 1947, p. 28, table J(2). Data on mortality from congenital syphilis strongly reinforces this picture. The mortality rate for syphilis in children under the age of one fell by 67 per cent in the period 1920-25 and by 90 per cent in the period 1920-38 (see, ibid.). 


\section{Roger Davidson}

Graph 1: Recorded deaths from syphilis, locomotor ataxia and general paralysis of the insane in Scotland, 1900-40. (Sources: Registrar-General for Scotland, annual reports.)

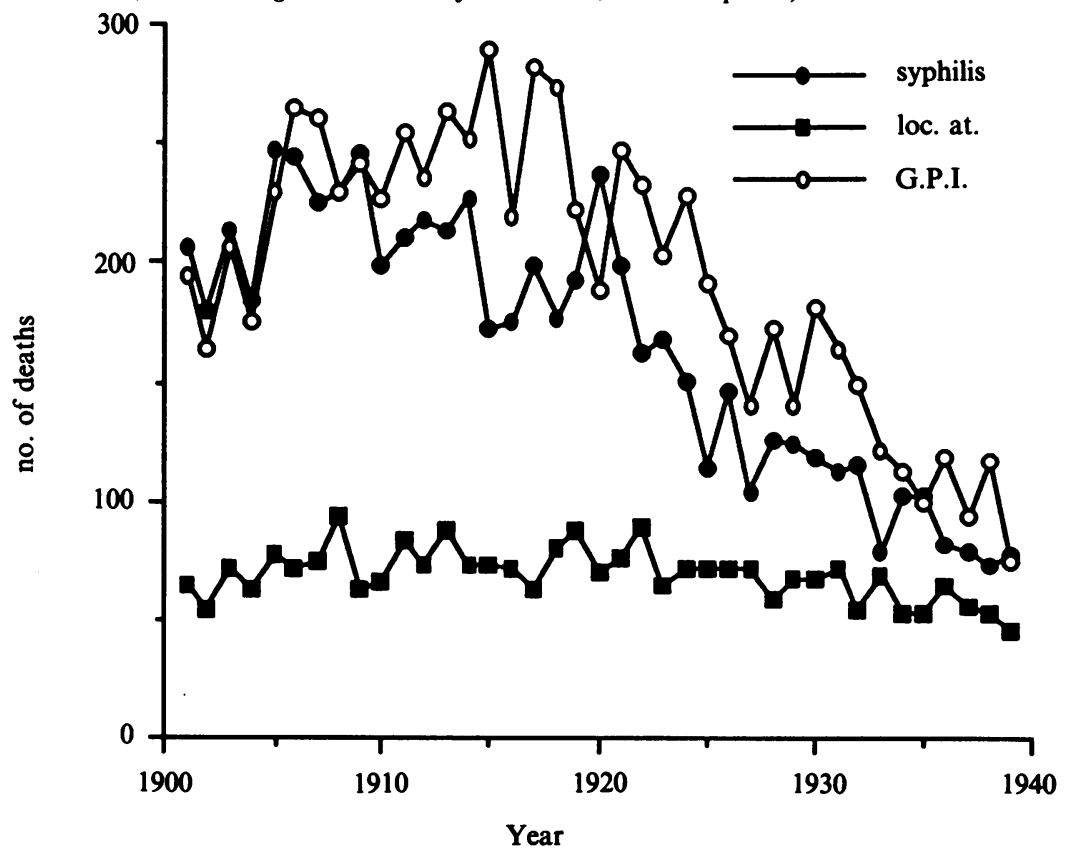

Graph 2: Scottish deaths per million of population from syphilis and parasyphilitic diseases, $1918-39$. (Sources: Registrar-General for Scotland, annual reports.)

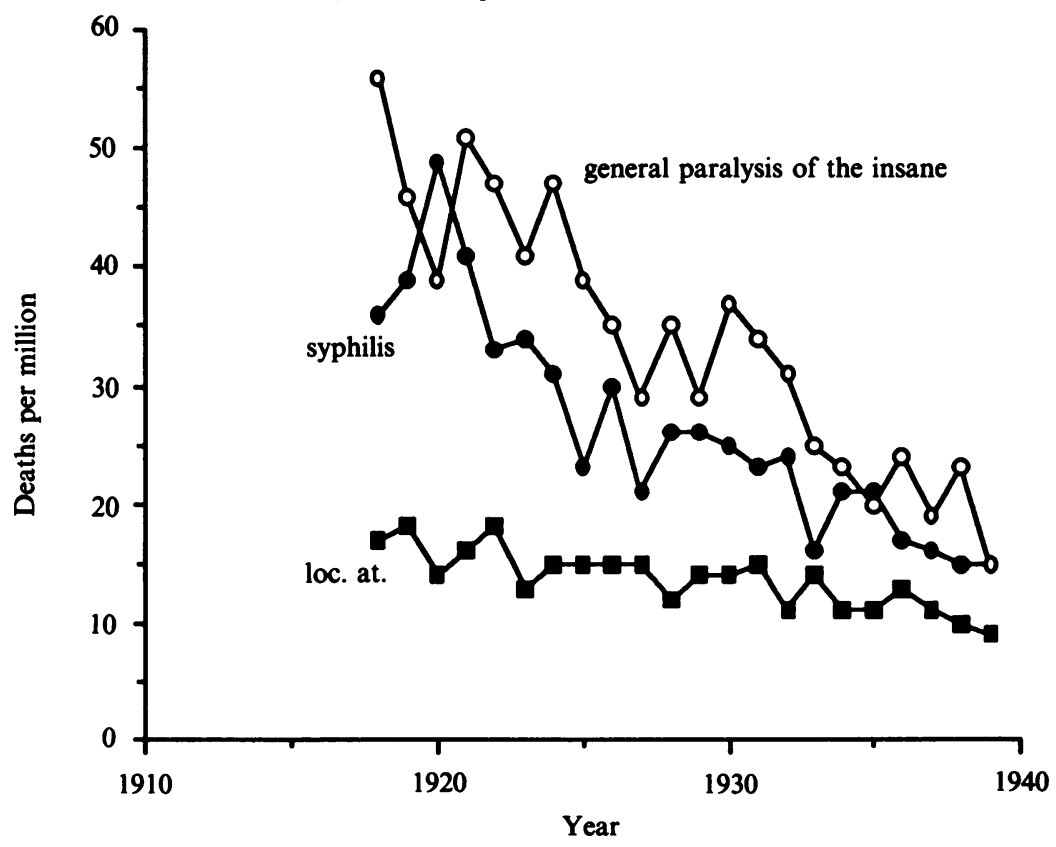


Graph 3: Deaths per million of population from locomotor ataxia and general paralysis of the insane in Scotland, and England and Wales, 1920-39. (Sources: Registrar-General for Scotland, annual reports; Registrar-General for England, statistical reviews.)

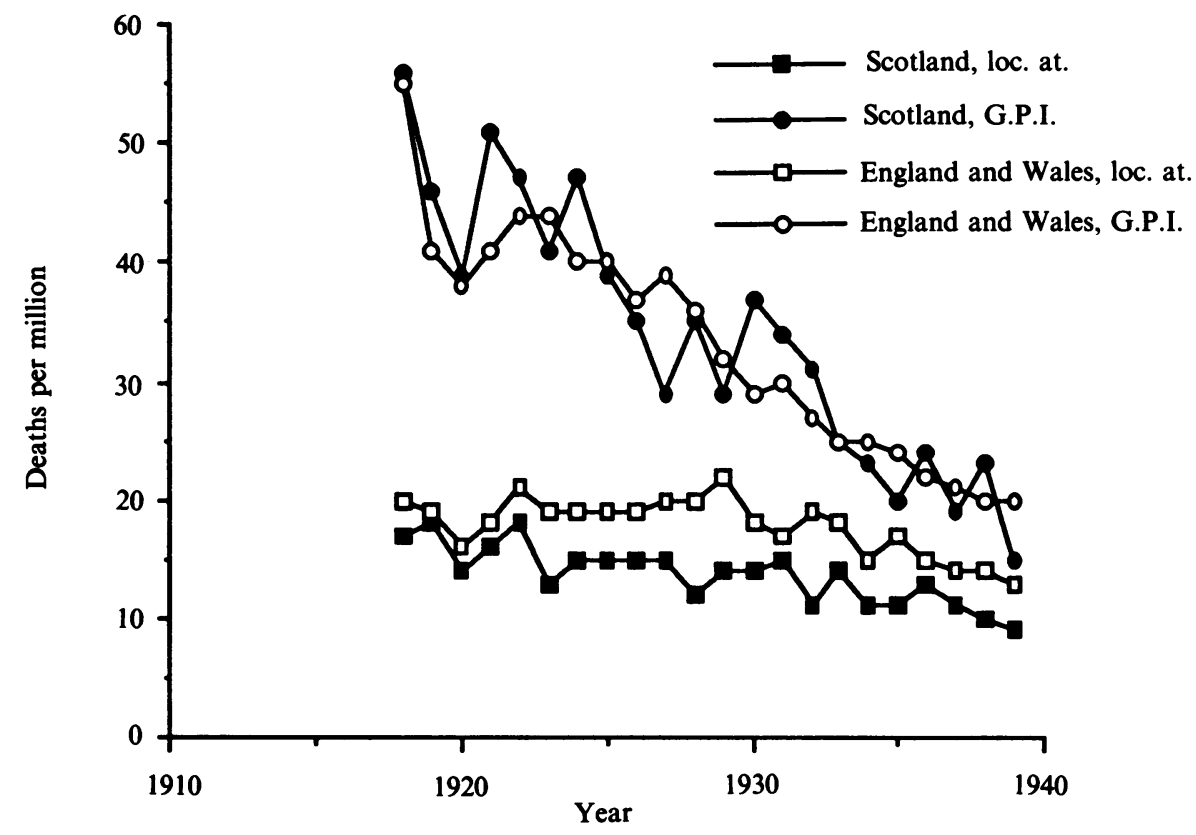

somewhat more volatile, a comparison of death rates for Scotland and for England and Wales (Graph 3) clearly reveals very similar falling trends in mortality from parasyphilitic diseases.

The task of estimating the relationship between mortality data and the incidence of venereal disease was highly problematic, especially at a time when new forms of treatment such as the use of arsephenamines were transforming the relationship between the morbidity and mortality rates of syphilis. However, inspired by contemporary debate over the issue and by a concern to counter complacency from the smaller local authorities, medical experts within the Scottish Board of Health sought to provide crude estimates.

Thus, Frederick Dittmar, Medical Inspector of the Board, attempted to establish the approximate extent of syphilitic infection within the community by aggregating along with syphilis a proportion of the mortality for a range of associated diseases. ${ }^{15} \mathrm{He}$ argued that the percentage represented by such deaths to total annual deaths would be "at least about the same, and possibly greater" than "the proportion of the population affected by syphilis". On this basis, he posited an incidence of syphilis within the Scottish community of circa 6 per cent for 1911-15. Similar calculations for selected interwar years indicate a steady fall to 3 per cent by the late 1930s (see Table 1).

\footnotetext{
${ }^{15}$ Dittmar, op. cit., note 11 above, pp. 45-55. These included locomotor ataxia, G.P.I., aneurysm; 50 per cent of deaths ascribed to premature birth, abortion, miscarriage, congenital debility, icterus, sclerema, other diseases of the spinal cord, softening of the brain, and angina pectoris; and 50 per cent of deaths under the age of 55 certified as cerebral haemorrhage, apoplexy and hemiplegia.
} 
Table 1: Estimated percentage of annual deaths ascribable to syphilis [Dittmar formula].

\begin{tabular}{ll}
\hline Year & $\%$ \\
\hline 1920 & 5.4 \\
1925 & 4.3 \\
1930 & 4.1 \\
1935 & 3.4 \\
1939 & 3.0 \\
\hline
\end{tabular}

(Sources: Dittmar, op. cit., note 11; Registrar-General for Scotland, annual reports.)

Meanwhile, his colleague, T. F. Dewar, sought to gain traction on the issue by exploiting medical evidence that between 2 to 3 per cent of syphilitic cases died of tabes and G.P.I., and that mortality rates from syphilis calculated upon this ratio would reflect the proportion of the living population infected at a previous date. ${ }^{16} \mathrm{On}$ the basis of assumptions about the average age at infection and expectation of life, Dewar's methodology yields a prevalence of syphilitic disease of c. 4.7 per cent for 1920 falling to c. 3.7 per cent of the population by 1925 . Interestingly, both the absolute level of syphilitic infection estimated according to Dewar's formula and its significant decline in the early 1920s are in substantial accord with Dittmar's estimates.

While such estimates were markedly lower than those of the Royal Commission on Venereal Diseases, they still indicated an alarming level of infection within the interwar Scottish community; especially, at a time when public health experts widely agreed that gonorrhoea was at least 3 to 4 times as prevalent as syphilis. ${ }^{17}$

\section{EVIDENCE FROM WASSERMAN AND OTHER REACTION TESTING}

More confident estimates of the incidence of syphilis in interwar Scotland might have been based upon Wasserman or other reaction tests. However, prevalence testing for epidemiological purposes was notably absent from contemporary health practice in Scotland. One major constraint was the lack of consensus within the medical profession over the reliability of the test and over its interpretation for the purposes of venereology. Knowledge of the "physical basis of the reactions" was still rudimentary and lack of standardization in the application of the Wasserman test rendered comparative analysis of findings hazardous. In particular, the value of Wasserman reactions in infants as an indicator of congenital syphilis was increasingly questioned. ${ }^{18}$ In addition, there were logistical and medico-legal problems involved in obtaining a random sample of blood donors. ${ }^{19}$ At best, an unselected sample of public hospital patients might be obtained, which inevitably reduced the validity of

\footnotetext{
${ }^{16}$ Dewar, op. cit., note 3 above, pp. 316-21.

${ }^{17}$ Dewar, ibid., p. 334; Dittmar, op. cit., note 11 above, p. 53; Edinburgh P[ublic] H[ealth] D[epartment], annual report, 1930, p. 74.

${ }^{18}$ Medical Research Committee, special report no. 14: the Wasserman test, London, HMSO, 1918, pp. 3-5; special report no. 78: the serum diagnosis of syphilis: the Wasserman and Sigma reactions compared, London, HMSO, 1923, p. 3; J. N. Cruikshank, 'Maternal syphilis as a cause of death of the foetus and of the new-born child', Medical Research Council, special report no. 82, London, HMSO, 1924, pp. 5, 23.

${ }^{19}$ Dewar, op. cit., note 3 above, p. 329.
} 


\section{Venereal disease in interwar Scotland}

Graph 4: Evidence from reaction tests in Scotland in the 1920s.

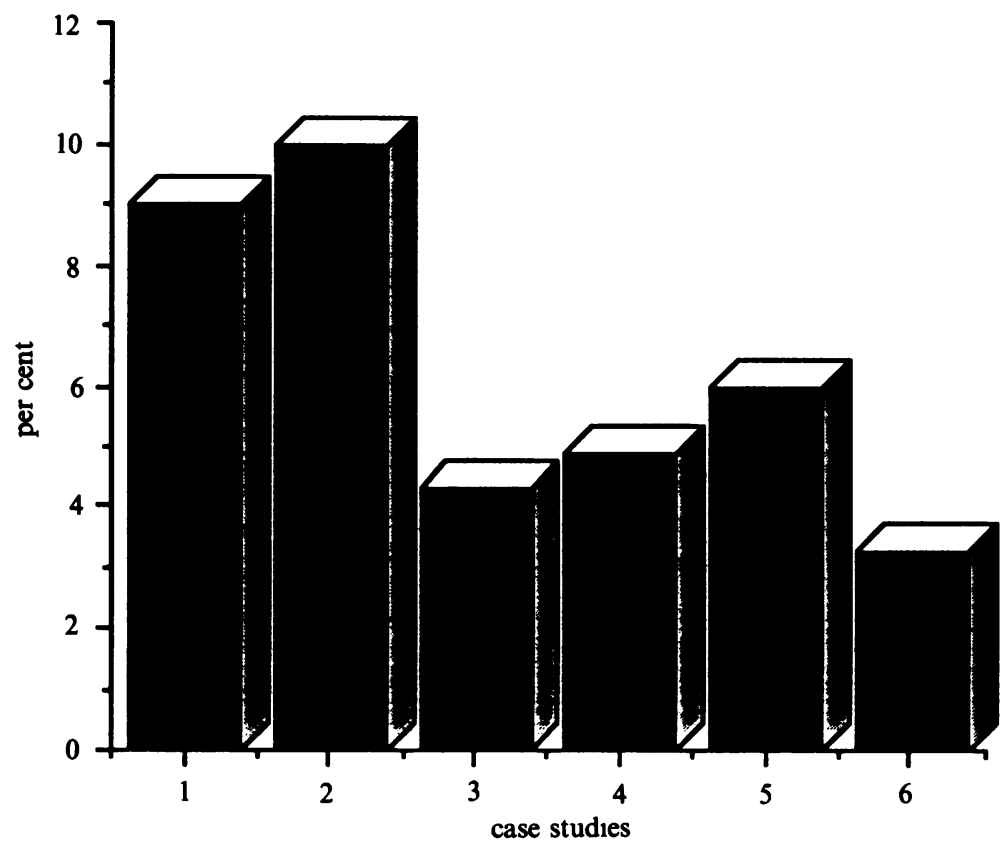

1). 1920-1: A. M. Kennedy, Royal Maternity Hospital Glasgow, unselected sample of 1881 women of "all classes except well-do-do"; incidence $9 \%$.

2). 1922: J. N. Cruikshank. Royal Maternity Hospital Glasgow; unselected sample of 1881 women of "hospital class"; incidence 9-10\%.

3). 1923: T. F. Dewar, small garrison town hospital; random sample of 141 patients from "lower and middle classes": incidence $4.3 \%$.

4). 1925: Glasgow ante-natal clinics, routine testing [sample size not known]; incidence $4.9 \%$.

5). 1925-6: Edinburgh Royal Maternity Hospital ante-natal clinic, unselected sample of 2000 women; incidence $6 \%$.

6). 1929: Glasgow ante-natal clinics, routine testing of 612 women patients; incidence $3.3 \%$.

reaction findings for estimating the incidence of venereal disease in the general population. ${ }^{20}$

None the less, a scatter of studies were undertaken in the $1920 \mathrm{~s}$, based primarily upon samples of maternal, placental and infantile blood taken at maternity hospitals and ante-natal clinics in Glasgow and Edinburgh from "the hospital class" (see Graph 4). Wasserman reaction tests yielded adult syphilis incidence figures varying from 3.3 per cent to 10 per cent and averaging 6.3 per cent. Dewar's attempt to investigate a genuinely random sample from an unnamed "moderately sized and centrally situated" Scottish "garrison town" yielded a finding of 4.3 per cent. ${ }^{21}$ Such samples again indicate a significant decline in the incidence of syphilis in Scotland during the 1920s.

${ }^{20}$ Cruikshank, op. cit., note 18 above, p. 7.

${ }^{21}$ Dewar, op. cit., note 3 above, pp. 321-9; J. N. Cruikshank, 'Syphilis as a cause of ante-natal death', Br. med. J., 1922, ii: 592-4; idem, op. cit., note 18 above, passim; The Medical Officer, XLIX, 1933, p. 249. 


\section{Roger Davidson}

Due to the growing practice within Scottish maternity hospitals of routinely testing all expectant mothers for syphilis, coupled with the increasing adoption of the more reliable Kahn precipitation test to supplement the Wasserman reaction test, the medical historian has available much firmer evidence for the 1930s. For example, statistics of testing undertaken at the Elsie Inglis Memorial Hospital and the Royal Maternity Hospital in Edinburgh reveal that during the period 1934 to 1938, some 1.99 per cent of patients were positive. For the same period, Glasgow ante-natal clinics yielded a positive rate of 1.85 per cent. ${ }^{22}$ In spite of the class and sex specificity of the data, figures for Glasgow (see Graph 5) also facilitate a longer-run perspective of trends in Scottish syphilis, especially when integrated with previous case studies involving Wasserman testing in the 1920s (see Graph 6). The interwar trend was sharply downwards with the fall concentrated in the 1920s. Thereafter, despite a temporary upswing in the incidence of syphilis in the early 1930s, the falling trend was sustained at a more modest rate. Over the whole period 1920-39, Scottish syphilis levels within these socio-economic groups are seen to have dropped by 80 per cent and by some 70 per cent by 1930 . Curiously, although such data constituted the most solid prevalence information available, they were rarely discussed by contemporary practitioners or policy-makers. Indeed, when in 1938 the Clinical Medical Officer in charge of the Edinburgh VD Scheme defended the retention of routine Wasserman tests for expectant mothers, he remained silent on their value for broader epidemiological research. ${ }^{23}$

Regrettably, the only data available based upon systematic examination of an unselected male population were obtained by the National Service Medical Boards in the Edinburgh area in 1916-17 without the use of Wasserman reaction tests. Examination of 10,000 recruits had identified venereal disease as "very rare" and "much less common than is generally supposed". The Medical Commissioners" report had concluded that: "No doubt many of the diseased conditions in heart, skin, nervous system and bones were late results of syphilis, but even so the prevalence of these [venereal] diseases did not amount to $3 \%$ in this district." ${ }^{24}$ It has been argued that such returns indicate that "contemporary fears of the prevalence of sexuallytransmitted disease were probably grossly exaggerated", ${ }^{25}$ but, as contemporary experts pointed out, the Medical Board examinations were largely anthropometric in focus and, without sample blood testing, could not capture the real extent of venereal disease in the Scottish community. ${ }^{26}$

\section{EVIDENCE FROM SCOTTISH VENEREAL DISEASE CLINICS}

The activity reports of the local authority venereal disease clinics established after 1916 represent another important source of information on the incidence and

${ }^{22}$ Edinburgh P.H.D., annual report, 1933, pp. 40-1; 1936, p. 52; 1937, p. 97; Glasgow M.O.H., annual reports, 1934, p. 206; 1935, p. 210; 1936, p. 189; 1937, p. 202; 1938, p. 186.

${ }^{23}$ Edinburgh P.H.D., annual report, 1938, pp. 125-7.

${ }^{24}$ P[ublic] R[ecord] O[ffice], NATS/1/13/M.54, Report of Medical Service Commissioners for Scotland, pp. $125,143$.

${ }_{25}$ Winter, op. cit., note 8 above, p. 236.

${ }^{26}$ Dewar, op. cit., note 3 above, p. 330. 


\section{Venereal disease in interwar Scotland}

Graph 5: Glasgow ante-natal clinics 1929-38; percentage of patients testing positive for syphilis. (Source: Glasgow M.O.H., annual reports.)

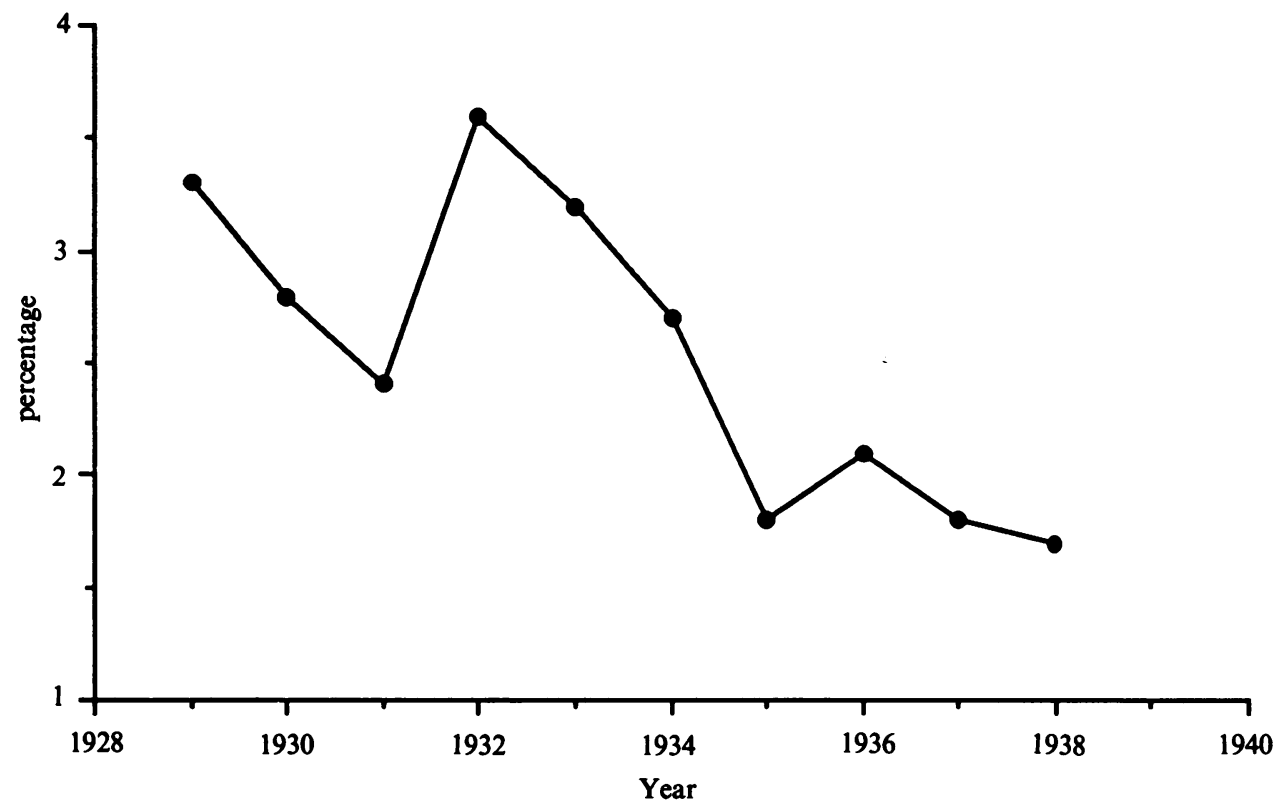

Graph 6: Incidence of syphilis in interwar Scotland based on reaction texts. (Sources: Glasgow M.O.H., annual reports; Dewar, op. cit., note 3; Cruikshank, op. cit., note 18.)

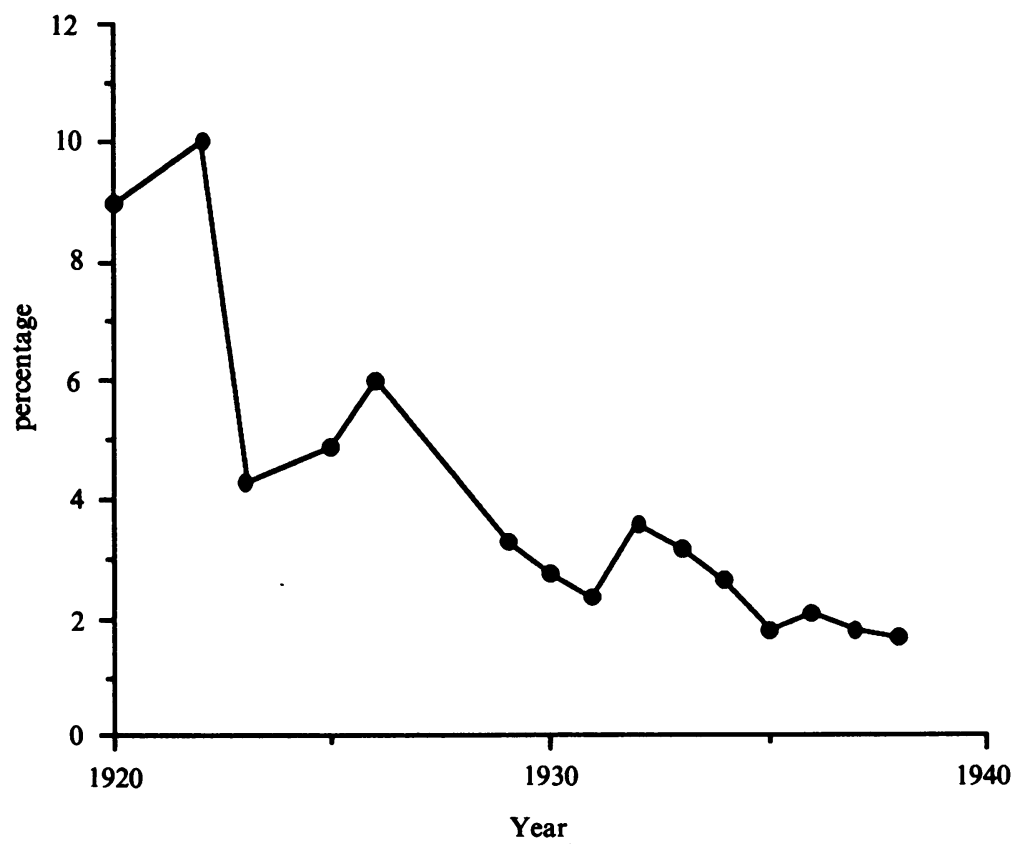


distribution of venereal disease in interwar Scotland. ${ }^{27}$ As a data base, such information does have significant limitations. The numbers attending clinics were not merely a reflection of shifts in the incidence of venereal disease. They often varied, both over time and between health authorities, according to the quality of the medical staff and the facilities provided, particularly in the early years of the service. ${ }^{28}$ They were also sensitive to shifts in public awareness of the seriousness of specific venereal infections, as in the upswing in gonorrhoea cases after $1927 .^{29}$ Likewise, the introduction of new diagnostic techniques could create the illusion of an upswing in the prevalence of disease, as with the impact in the 1930s of routine ante-natal reaction testing upon the numbers of females with syphilis. ${ }^{30}$ The use of "new cases" as an index of the incidence of sexually transmitted diseases was also complicated by the difficulty of distinguishing new infections from re-infections or from secondary manifestations of old infections previously untreated, and by the tendency of many patients to migrate "between several different clinics." 31

Above all, it was widely agreed by medical authorities that the numbers attending the clinics were only a proportion of those infected within the community. Dittmar estimated that at least as many cases of venereal disease were treated by private practitioners as came for treatment to public treatment centres. ${ }^{32}$ Moreover, despite the provisions of the 1917 Venereal Disease Act prohibiting all persons except qualified medical practitioners from treating venereal disease, or prescribing or advising in connection with it, a significant amount of unqualified treatment persisted. ${ }^{33}$ David Lees, the venereologist in charge of Edinburgh's clinics, considered that in the mid-1920s there were still more people obtaining unqualified and illicit treatment than having recourse to the clinics; a view he reiterated in his annual report for $1930 .^{34}$ The low ratio of gonorrhoea to syphilis in the cases attending Scottish clinics was viewed as convincing evidence of the amount of infection remaining untreated or unprofessionally treated within the community. ${ }^{35}$ While the known relative incidence of the two diseases was of the order of between $3: 1$ and $4: 1$, the ratio experienced in the clinics varied from $0.80: 1$ in $1921-2$ to $1.65: 1$ by the early $1930 \mathrm{~s}$, and was still only $1.92: 1$ in $1937 .{ }^{36}$

\footnotetext{
${ }^{27}$ For a review of the development of the VD clinic system in Scotland, see S[cottish] B[oard of] H[ealth], annual report, 1924, pp. 62-70.

${ }^{28}$ Dewar, op. cit., note 3 above, p. 329; S.B.H., annual reports, 1921, p. 25; 1927, p. 107; Aberdeen M.O.H., annual reports, 1922, p. 85; 1935, pp. 49-50; 1936, p. iv; Dundee M.O.H., annual report, 1929, p. 24.

${ }^{29}$ S.B.H., annual reports, 1927, p. 121; 1928, p. 219; Aberdeen M.O.H. annual report, 1935, pp. 49-50. It should also be noted that culture methods for the diagnosis of gonorrhoea were not well advanced in the interwar period and many cases of non-specific genital tract infection were probably misdiagnosed as gonorrhoea.

${ }^{30}$ Edinburgh P.H.D., annual report, 1933, p. 79; Dundee M.O.H., annual report, 1937, p. 21.

31 See C. N. Rolfe, 'The prevention of venereal disease', J. State Med., 1926, 34: p. 356.

${ }^{32}$ Dittmar, op. cit., note 11 above, p. 53; S.B.H., annual reports, 1924, p. 30; 1927, p. 112.

${ }^{33}$ S.B.H., annual report, 1926, p. 82; Dewar, 'On the incidence of venereal disease', p. 330; Edinburgh P.H.D., annual report, 1922, p. 43.

${ }^{34}$ Dewar, op. cit., note 3 above, p. 330; Edinburgh P.H.D., annual report, 1930, p. 74.

${ }^{35}$ See, e.g., S.B.H., annual reports, 1926, p. 82; 1928, p. 218 ; Edinburgh P.H.D., annual reports, 1921, p. 40; 1930 , p. $74 ; 1933$, p. 80.

${ }^{36}$ S.B.H./S.D.H., annual reports.
} 


\section{Venereal disease in interwar Scotland}

Graph 7: Scottish VD clinics: index of new cases, 1922-37. (Sources: S.B.H./S.D.H., annual reports.)

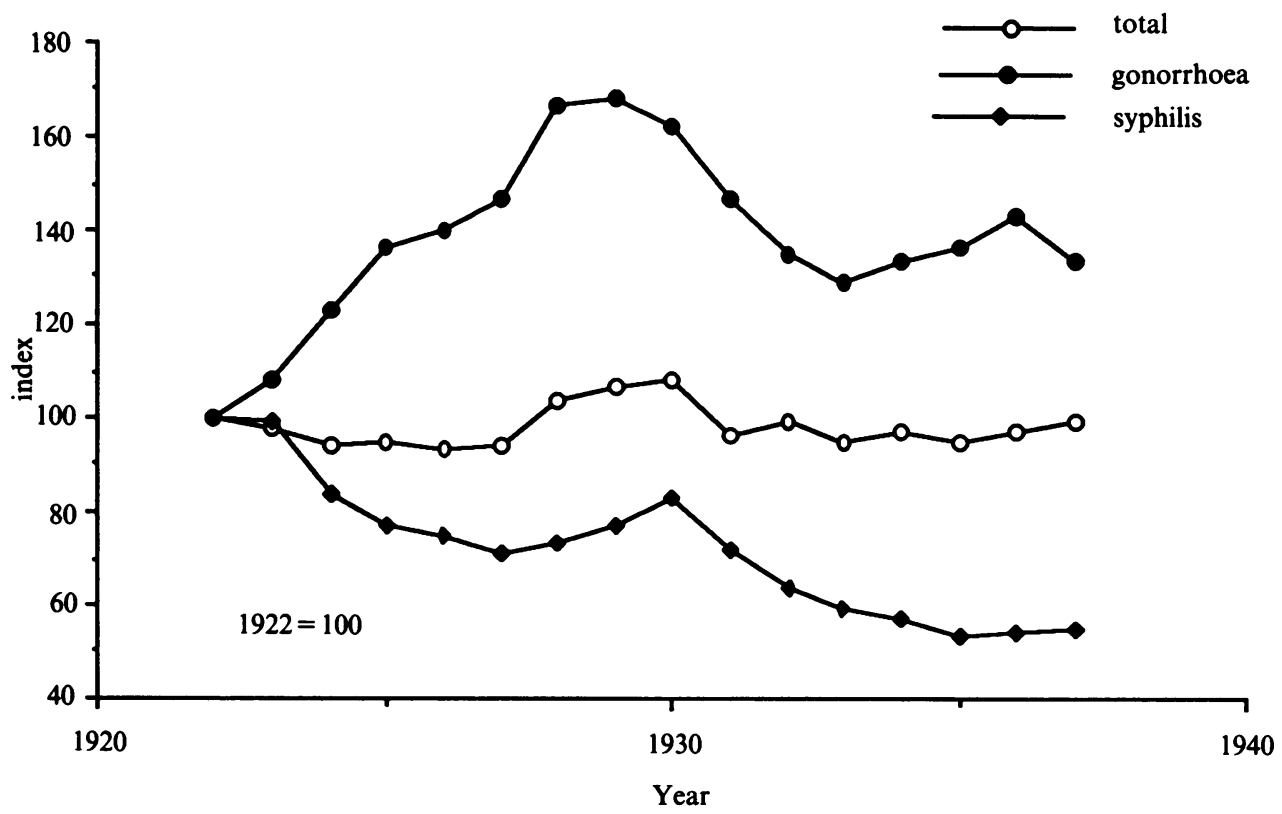

Graph 8: Breakdown of venereal cases at Scottish clinics, 1922-37, by type of infection. (Sources: S.B.H./S.D.H., annual reports.)

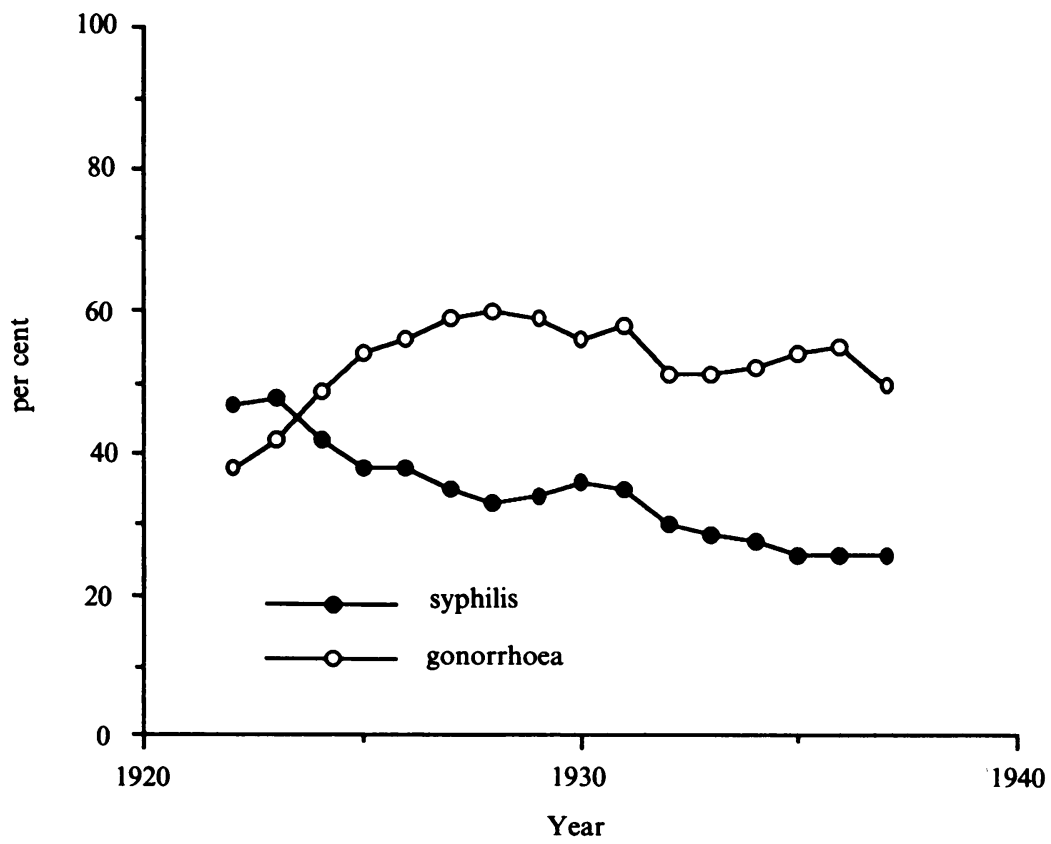




\section{Roger Davidson}

None the less, despite these limitations, the data collated by the venereal disease clinics furnish the medical historian with some useful indicators of medium and long-term trends in the temporal, sexual, and geographical incidence of venereal diseases in interwar Scotland. An index of the volume of new cases diagnosed as having venereal disease (Graph 7) reveals a fairly level profile of activity for total numbers, except for an upswing in the late 1920s. In contrast, the specific indices for syphilis and gonorrhoea cases are widely divergent. Both display upswings in the late 1920s followed by sharp downturns in the early 1930s, but whereas gonorrhoea is on a rising trend, the trend for syphilis is sharply downwards. This divergence is clearly reflected in changes in the relative incidence of the two infections in patients attending the clinics (Graph 8). At the start of the 1920s, syphilis was the dominant disease, representing some 48 per cent of infected patients, but by 1924, gonorrhoea already exceeded syphilis as a proportion of Scottish cases by some 7 per cent. By 1928, the differential had widened to 28 per cent and remained on average at around 25 per cent for the whole of the 1930s; the proportion of patients suffering from syphilis in 1937 having fallen to 26 per cent.

A breakdown of Scottish VD cases attending clinics according to gender (Graphs 9-11) reveals a rising trend in the numbers of both male and female patients in the 1920s. However, female numbers diverged sharply downwards after 1932. The long-term downtrend in syphilis cases was shared by both sexes but their short-term upswing in the late 1920 s was primarily a male phenomenon. The volume of male and female gonorrhoea cases displayed a similar profile over time with a substantial and sustained rise to $c$. 1930, then a downturn to the mid-30s before levelling out on a par with the mid-1920s. However, the index of female gonorrhoea cases is markedly more volatile than that for male patients.

The sex distribution of venereal disease remained remarkably constant (see Graph 12). Throughout the interwar period, venereal disease as witnessed at Scottish clinics was a predominantly male disease, male cases constituting between 63 and 69 per cent of all infected cases. However, this imbalance was, in the main, a function of gonorrhoea. Whereas the sex ratio of male/female syphilis was in the order of 53:47 for the 1920s and 55:45 for the 1930s, the ratio for gonorrhoea was respectively 75:25 and 73:27.

Clinic data also indicate that interwar venereal disease in Scotland was predominantly an acquired disease of adolescent and adult age groups. On average, only about 7 per cent of new cases diagnosed as infected were aged under 15 years, some 31 per cent were between 15 and 25, and 62 per cent were over 25 . Moreover, on trend, the age distribution of venereal infection shifted towards the over $25 \mathrm{~s}$, especially in the 1920s. This age group accounted for 51 per cent of new cases in 1922, for 64 per cent in 1930 and for 67 per cent in $1937 .{ }^{37}$

\footnotetext{
${ }^{37}$ S.B.H./S.D.H., annual reports. In part, this was due to the more immediate and effective treatment of congenital infections such as ophthalmia neonatorum. It should be noted that from the early 1920s, provision existed in Edinburgh, Glasgow and Dundee for the diagnosis and treatment of VD at many Maternity and Child Welfare Centres. However, new cases treated at these centres were included in the overall returns for the VD schemes and these arrangements did not therefore distort the sex and age distribution of their data. See, Glasgow M.O.H., annual report, 1926, pp. 155-8; Edinburgh P.H.D., annual
} 


\section{Venereal disease in interwar Scotland}

Graph 9: Index of new VD cases by gender at Scottish clinics, 1922-37. (Sources: S.B.H./S.D.H., annual reports.)

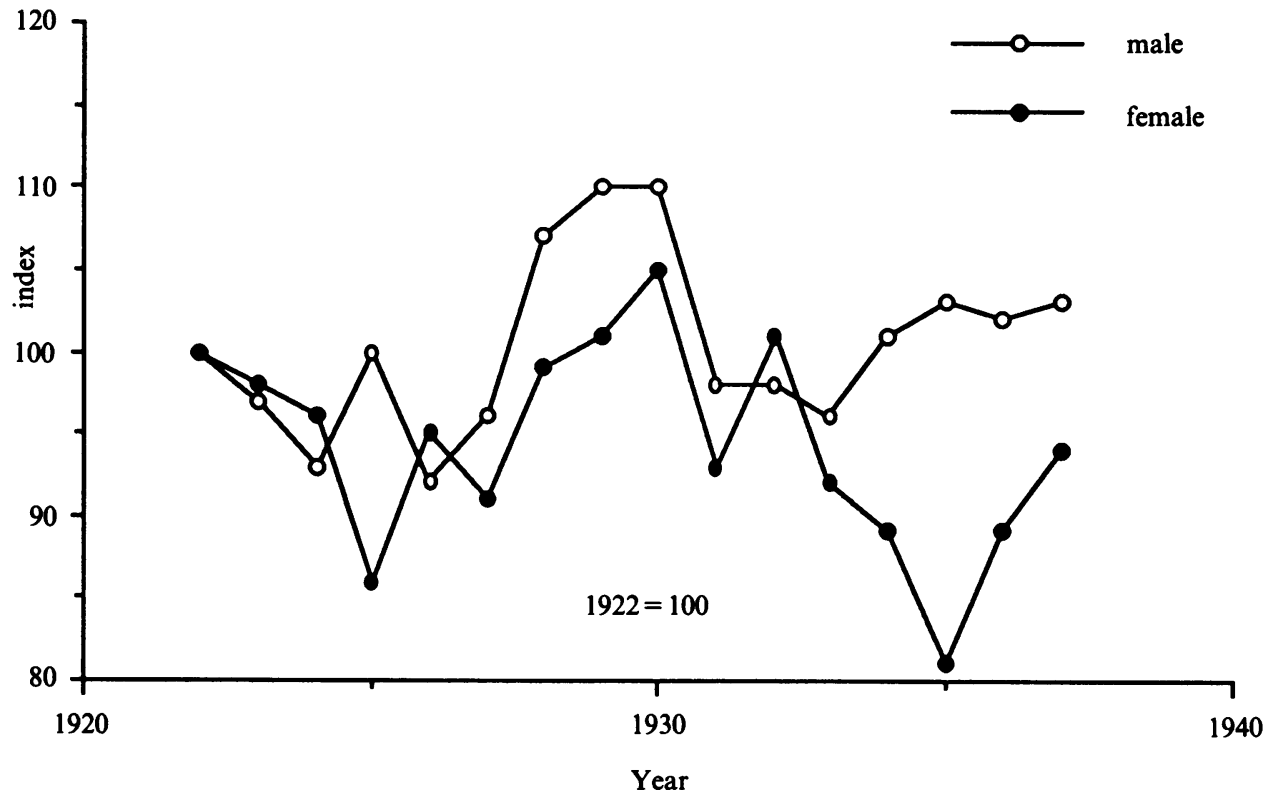

Graph 10: Scottish clinics: index of new syphilis cases by gender, 1922-37. (Sources: S.B.H./S.D.H., annual reports.)

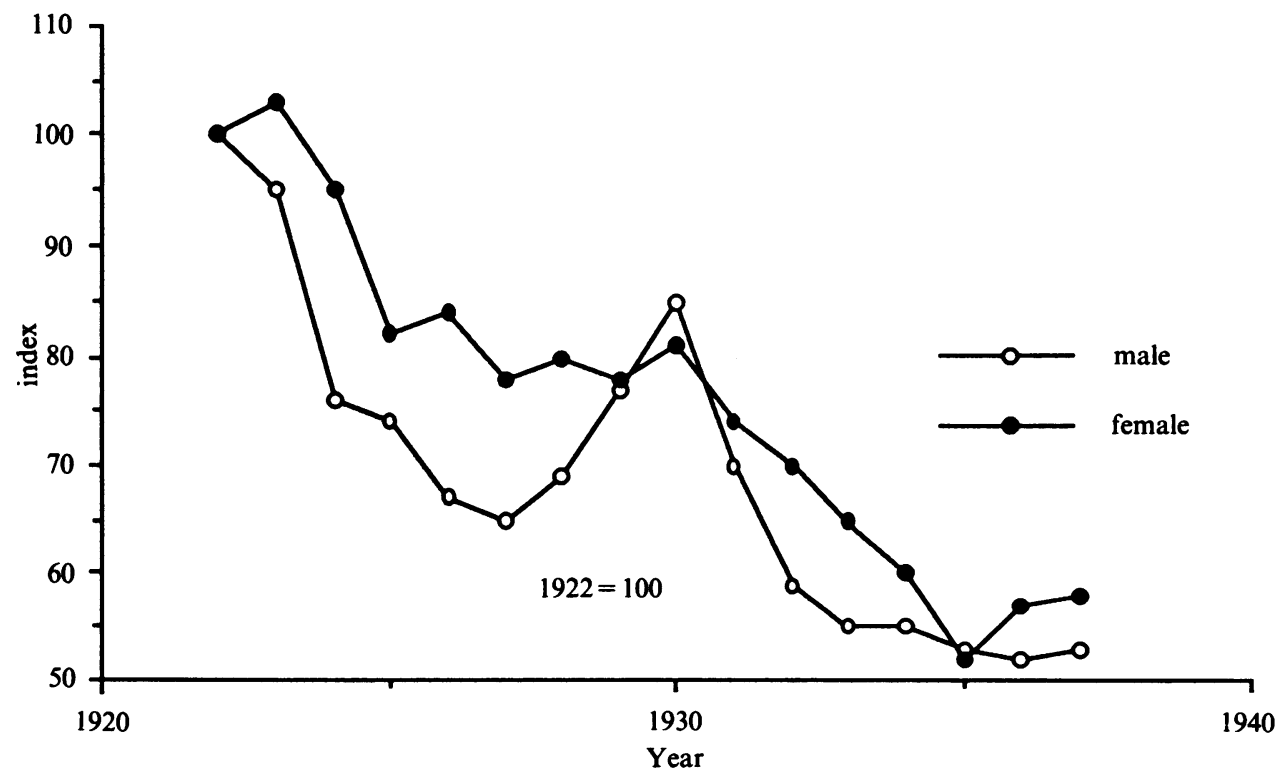




\section{Roger Davidson}

Graph 11: Scottish clinics: index of new gonorrhoea cases by gender, 1922-37. (Sources: S.B.H./S.D.H., annual reports.)

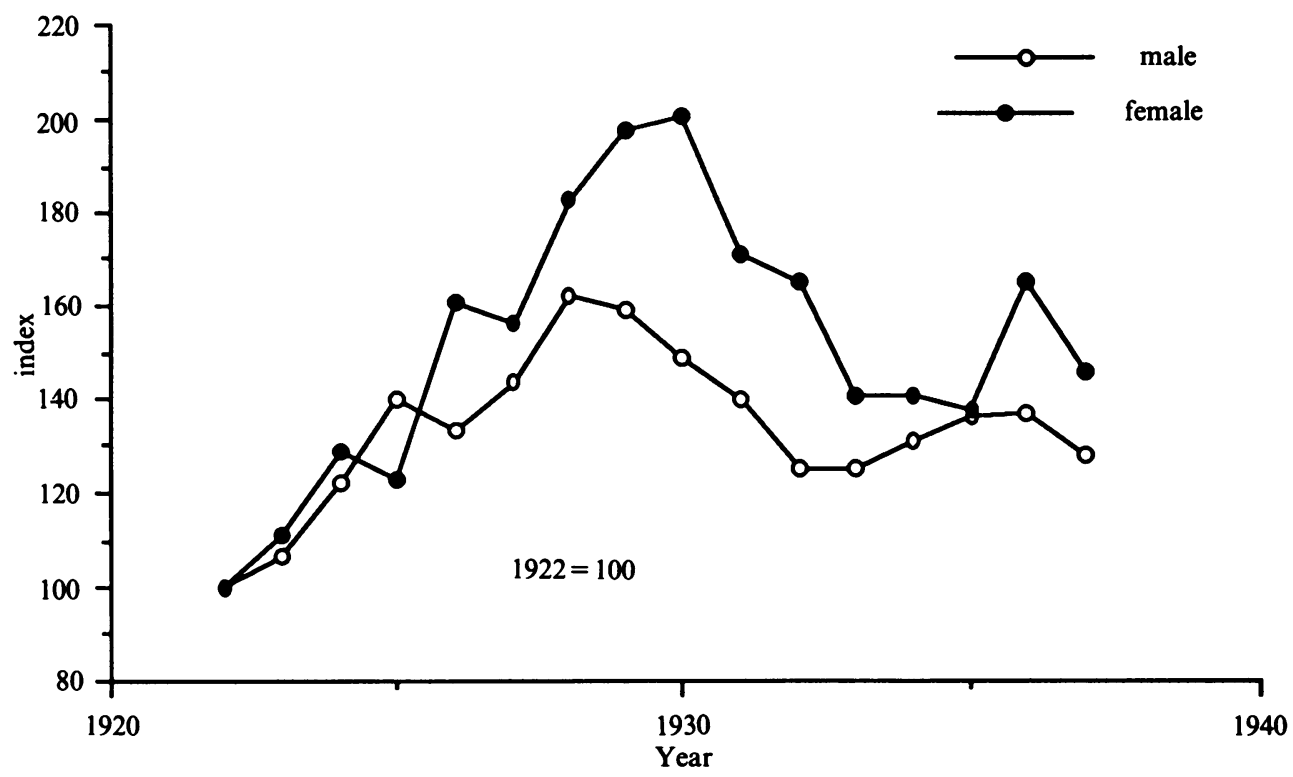

Graph 12: Scottish VD clinics: percentage breakdown by gender of new cases, 1922-37. (Sources: S.B.H./S.D.H., annual reports.)

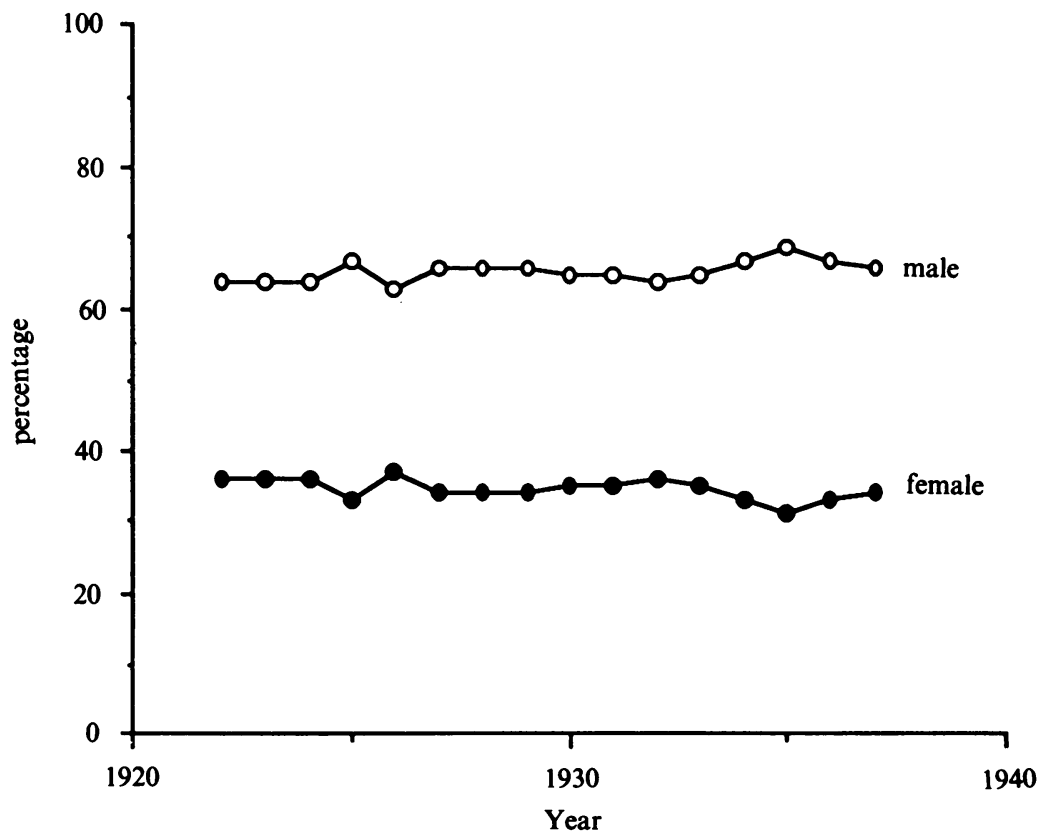


Comparative analysis of Scottish and English clinic data reveals a very similar configuration in the interwar indices for total numbers of new cases. There is also a close symmetry between the time series for new syphilitic cases in the two countries. For gonorrhoea, the marked rise in numbers in the 1920s is a common feature but is more pronounced in Scotland (a rise of some 68 per cent as compared with 36 per cent). In terms of the gender distribution of clinic cases, England was throughout the interwar period more male orientated (averaging 74 per cent as compared with 65 per cent for Scotland), the divergence largely being accounted for by variations in the gender-specificity of syphilis. The gender ratios of male to female syphilis during the interwar period in Scotland and England were 54:46 and 62:38 respectively. ${ }^{38}$

How far a comparison between clinic data for specific cities can illuminate real variations in the regional incidence of interwar venereal disease in Scotland is problematic. Diagnostic and recording practices were rarely standardized. ${ }^{39}$ Local shifts in the organization or quality of provisions often produced significant fluctuations in both the volume and gender of new cases with institutional considerations clearly outweighing epidemiological factors. ${ }^{40}$ None the less, comparative data for Edinburgh, Glasgow, Aberdeen and Dundee (Graph 13) do furnish some indication of how far Venereal Disease Schemes diverged in the pattern of cases encountered. ${ }^{41}$

Indexed time series of all new venereal cases at clinics in Glasgow and Edinburgh display very similar profiles, fluctuating modestly around a shallow downtrend. In contrast, activity levels at Dundee and Aberdeen clinics exhibit for the bulk of the interwar period wider variations around a sharply rising trend. The data would suggest that this divergence was primarily a function of proportionately sharper rises in gonorrhoea north of the Forth. All the cities conform to the national trend in the changing proportion of venereal disease attributable to syphilis, although Edinburgh's short-term upswing from $1927-31$ is markedly more pronounced. Similar series for gonorrhoea also broadly follow the Scottish pattern, but with significant variations in their range. A good deal of this variation had little to do with the relative incidence of the disease and more to do with the comparative rigour with which non-specific venereal infections were classified.

Gender-specific time series of the volume of all new cases reveal that the divergence in activity levels between Aberdeen and Dundee on the one hand, and Glasgow and Edinburgh on the other, was both a male and a female phenomenon. However,

report, 1920, p. xx; Dundee M.O.H., annual report, 1924, p. 116. In other Scottish cities, cases continued to be referred to the VD clinics from the maternity hospitals, child welfare centres, and school medical services.

${ }^{38}$ S.B.H./S.D.H. and English Ministry of Health, annual reports.

${ }^{39}$ Dundee M.O.H., annual report, 1921, p. 38.

${ }^{40}$ Dundee M.O.H., annual report, 1922, p. 38; Aberdeen M.O.H., annual report, 1922, p. 85.

${ }^{41}$ These cities accounted for some 84 per cent of new Scottish cases in 1922 with Glasgow by far the most important contributor (55 per cent) followed by Edinburgh (16 per cent), Dundee ( 9 per cent) and Aberdeen ( 4 per cent). This rank order remained throughout the interwar period, but while Aberdeen and Dundee slightly increased their percentage share of new cases, Glasgow's and Edinburgh's share declined sharply by 1930 (to 10 per cent and 36 per cent) and gained only 2 percentage points thereafter, reflecting the increasing spread of venereal disease facilities outwith the major city centres. 
Graph 13: Index of new VD cases at Scottish city clinics, 1920-38. (Sources: Edinburgh, Glasgow, Aberdeen and Dundee M.O.H., annual reports.)

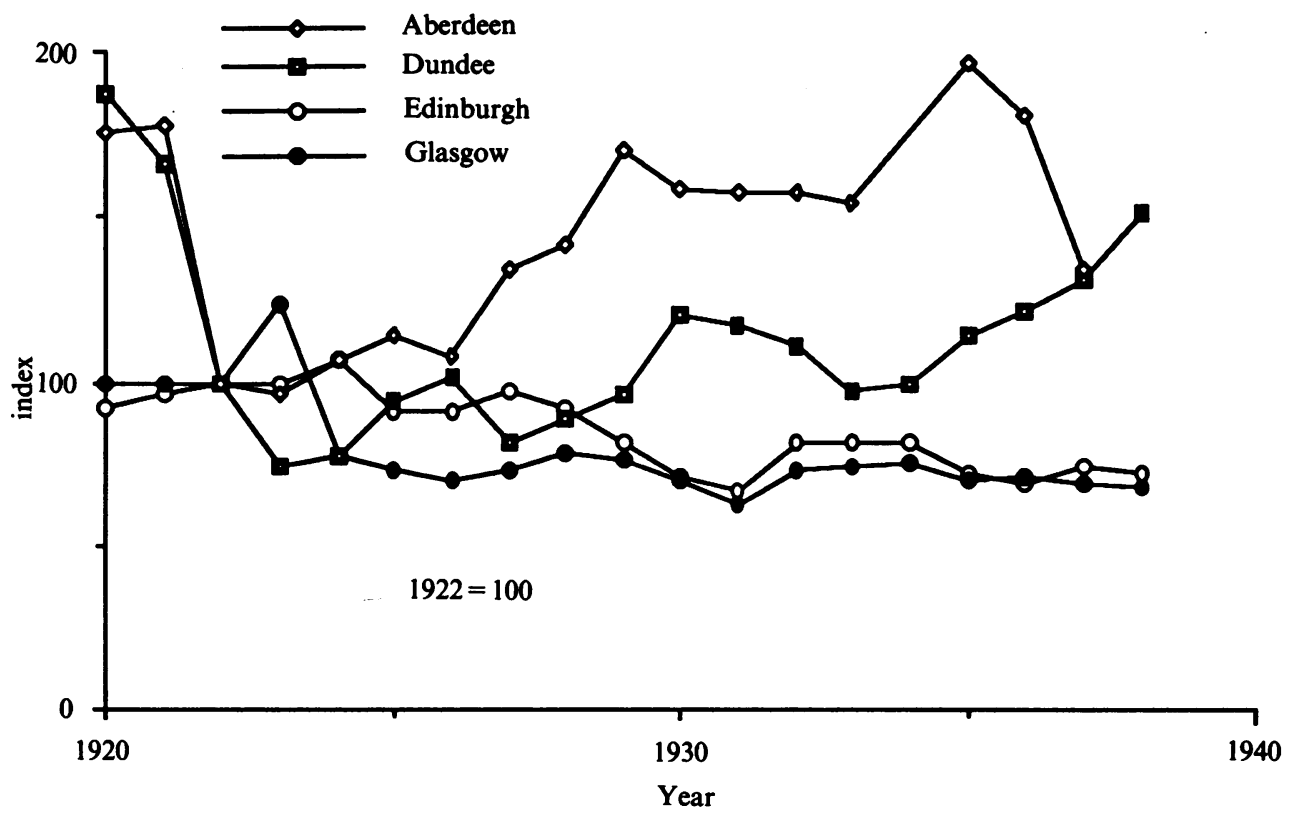

throughout the interwar period, the ratio of cases in Edinburgh and Aberdeen was markedly more skewed towards men than in Glasgow and Dundee, and especially so in the late 1920s and the mid-1930s. Their respective inter-war ratios were Edinburgh 74:26, Aberdeen 74:26, Glasgow 67:33, and Dundee 60:40. The substantially greater number of female cases in Dundee, arguably in part a function of its demographic structure and distinctive labour market, appears to have been true of both syphilis and gonorrhoea, whereas for Glasgow, except for the early 1930s, it was primarily a feature of gonorrhoea. The four cities broadly conformed to national trends in the age structure of their venereal cases. However, there were variations, especially at the lower end of the age-range. Thus, Dundee had 9 per cent of cases under the age of fifteen as compared with 4 per cent in Edinburgh, while the shift towards the upper age group (25+) during the 1920s, most marked in Glasgow and Edinburgh, was noticeably absent in Dundee.

The use of data from the venereal disease clinics to measure the actual proportion of Scottish interwar society suffering from sexually transmitted disease is even more problematic. On the assumption held by contemporary venereologists that those seeking private treatment from practitioners for syphilis represented some third of the numbers attending public clinics and that the ratio of gonorrhoea to syphilis was in the order of 3-4:1, a very crude lower estimate of the extent of new infection within the population can be obtained, (see Tables $2 \mathrm{a}$ and $2 \mathrm{~b}$ ). The data reveal the marked regional variations in levels of infection, with Glasgow 2 to 3 times the national incidence, and their significant decline over the interwar period, with levels of infection in the 1930s only half those prevailing in the 1920 s in the major urban centres. 


\section{Venereal disease in interwar Scotland}

Table 2a: Estimated proportion of the Scottish population newly infected with syphilis and gonorrhoea 1922-37: assuming ratio of gonorrhoea to syphilis of 3:1.

\begin{tabular}{cccc}
\hline & $\begin{array}{r}1922-37 \\
\text { annual \% }\end{array}$ & $\begin{array}{r}1922-29 \\
\text { annual \% }\end{array}$ & $\begin{array}{c}1930-7 \\
\text { annual \% }\end{array}$ \\
\hline Scotland & 0.41 & 0.47 & 0.35 \\
Glasgow & 0.79 & 1.05 & 0.57 \\
Edinburgh & 0.67 & 0.90 & 0.42 \\
\hline
\end{tabular}

Table $2 b$ : Assuming ratio of gonorrhoea to syphilis of 4:1.

\begin{tabular}{cccc}
\hline & $\begin{array}{r}1922-37 \\
\text { annual \% }\end{array}$ & $\begin{array}{c}1922-29 \\
\text { annual \% }\end{array}$ & $\begin{array}{c}1930-7 \\
\text { annual \% }\end{array}$ \\
\hline Scotland & 0.51 & 0.58 & 0.44 \\
Glasgow & 0.98 & 1.30 & 0.71 \\
Edinburgh & 0.84 & 1.12 & 0.53 \\
\hline
\end{tabular}

\section{CONCLUSION}

By the standards of the later twentieth century, the levels of venereal infection in interwar Scotland indicated by this paper were relatively high. Comparative data from clinics would suggest that the incidence of syphilis and gonorrhoea in the later 1920 s and 1930s was some 4 to 6 times greater than that for the period 1950-80. ${ }^{42}$ Historical comparisons of ante-natal Wasserman reaction testing are highly suspect and far less accessible, but evidence from the Edinburgh Royal Infirmary points to a very similar ratio between later interwar and postwar infection rates. ${ }^{43}$

None the less, for the medical and social historian, the evidence presented above, for all its deficiencies, does indicate a dramatic improvement in the health and quality of life for a significant minority of the Scottish community after the First World War. In particular, all the indicators suggest that there was a marked fall in the incidence of syphilis as a killing and disabling disease as compared with levels prevailing both before and during the First World War, although meaningful time series for infectivity within the civilian population prior to 1918 are impossible to construct. ${ }^{44}$ Certainly, interwar medical authorities and politicians who continued to cite the estimates of the Royal Commission on Venereal Diseases were grossly exaggerating the extent of syphilitic infection within the community, and the intuition of Glasgow's Medical Officer of Health in 1934 that the prevalence figure of 10 per cent quoted by the Commission "might now be put at from three to four per cent" appears more consistent with the available facts. ${ }^{45}$

The social implications of the gonorrhoea evidence are more difficult to determine. The rising incidence of new cases was a function not only of its prevalence but of

\footnotetext{
${ }^{42}$ S.B.H./S.D.H., annual reports; Communicable diseases (Scotland) Unit: annual summaries of sexually transmitted disease.

${ }^{43}$ Edinburgh P.H.D., annual reports.

${ }^{44}$ See P.R.O. MH 55/195, Report by Dr J. P. Candler on 'The prevalence of syphilis'. The fall in the recorded incidence of syphilis is the more notable given that one might expect the continuing development of a nation-wide system of public clinics to have inflated the numbers registered for treatment.

45 Glasgow M.O.H., annual report, 1934, p. 10.
} 
improved medical facilities and the growing public awareness of the seriousness of the disease. Perhaps the most depressing feature of the Scottish data was the continuing preponderance of male patients receiving treatment for gonorrhoea at the clinics, varying between 75-80 per cent of new cases throughout the interwar period, despite the view of public health officials and general practitioners that its incidence within the community was more even between the sexes. ${ }^{46}$ While health standards for the mass of the population were steadily improving, ${ }^{47}$ this "dark figure" of unreported and untreated infection represented a lasting and significant threat to the health and fertility of Scottish women.

Equally significant was how little of the available information on the occurrence of sexually transmitted diseases in interwar Scotland was utilized by contemporary health administrators and policy-makers. In part, this was due to an understandable professional reluctance to endorse estimates based on evidence, whether it be mortality returns, reaction tests or clinic data, that was partial and contaminated by medical, social, and institutional factors. It also stemmed from the reluctance of central government to fund systematic prevalence research and to impose standardized screening procedures for epidemiological purposes upon the general community that involved invasive techniques such as blood testing. ${ }^{48}$ However, the primary reason was that the shifting medical priorities of Scottish venereologists and health officials initiated a switch in investigative focus from aggregative measures of the incidence of venereal diseases to intensive analysis of the extent and repercussions of "default" from treatment.

In the immediate post-war years, the major concern of the Scottish Board of Health was to ensure that local authorities complied with the Venereal Disease Regulations of 1916 and established voluntary schemes for the provision of treatment. ${ }^{49}$ In this task, estimates such as those of the Royal Commission on Venereal Diseases and those of Cruikshank, Dewar and Dittmar had considerable persuasive value. However, by the mid-1920s, as it became apparent that, despite substantial improvements in diagnosis and treatment, the rate of decline in syphilis was slowing while levels of detected gonorrhoea infection were steadily rising, the Scottish medical establishment became increasingly preoccupied with the number of patients defaulting from treatment, in the belief that this was the major factor determining the "stubborn" level of infection within the community. Evidence from Scottish VD clinics indicated that around one-third of patients failed to complete their course of treatment, while another quarter withdrew before a final test of cure. ${ }^{50}$ Levels of

\footnotetext{
${ }^{46}$ See, e.g., Glasgow M.O.H., annual reports, 1923, p. 116; 1932, p. 134; Edinburgh M.O.H., annual reports, 1934 , p. $71 ; 1936$, p. 83 . The main reason advanced by contemporary observers for the relatively low take-up of Scottish VD treatment facilities by women with gonorrhoea was the ignorance of many women of their infection given the "slight" symptoms manifested in the early stage of the disease. Additional factors cited were the lack of "gravity" attached to the gonococcal infection by many patients and by some general practitioners, the lack of a "definite specific" and standard of cure for the disease, and the logistical problems of seeking and sustaining treatment without the knowledge of relatives and the local community.

47 J. Stevenson, British society 1914-45, London, Penguin, 1984, ch. 7.

${ }^{48}$ See P.R.O., M.H. 55/1329, correspondence relating to the implementation of the Public Health (VD) Regulations 1916.

${ }_{49}$ S.B.H., annual reports, 1920-24.

so Ibid., 1921-30.
} 
default varied markedly with Glasgow clinics having the highest default rate, averaging some 65 per cent for the period 1921-29. ${ }^{51}$ Even in Edinburgh, which was recognized as having the most advanced treatment and "follow-up" facilities in the country, a default rate for the 1920 s of 43 per cent was recorded. ${ }^{52}$

The high incidence of "default" offended Scottish medical opinion in several respects. At a time of public expenditure cuts and increasing awareness of the health costs associated with acquired and congenital venereal diseases, it was perceived as an unacceptable waste of public funds. ${ }^{53}$ It also compromised the efforts of the Venereal Disease Schemes to combat a major threat to public health and national efficiency. Dr William Robertson, Medical Officer of Health for Edinburgh well captured the frustration of the Council's Venereal Disease Medical Officer in his report for 1926:

Those who believe that venereal disease can be adequately controlled by present methods, coupled with moralising and the offering of advice, do not understand our difficulties. For every one who may learn a lesson from bitter experience, there are more who either pay no heed to advice or do not care. When the world becomes a Utopia of Hygiene, we shall begin to dismiss our preventive staffs. We have a long road to travel before we reach that ideal condition of affairs. Our hands are tied when we attempt to deal thoroughly with venereal maladies. The situation is absurd. It is monstrous to think that we should be compelled to watch disease being spread before our very eyes. Under present conditions, we are unable to compel the spreaders of disease to submit to treatment, and those whom we have every reason to believe are neglectful are left alone because we have no power to enforce treatment. ${ }^{54}$

Above all, with its associated sexual promiscuity and "venereal recidivism", a high incidence of default ran counter to the moral objectives of the social hygiene movement in Scotland, with its stress on self-control and discipline for racial progress; aims broadly shared by many experts within the public health service. Scottish public health reports in the 1920 s repeatedly identified the defaulter as a sexually regressive recidivist requiring coercive measures. ${ }^{55}$ In the view of Dr David Lees and Dr R. J. Peters, Venereal Medical Officers for Edinburgh and Glasgow, the sexual intemperance of defaulters was breeding just that "casual outlook on venereal disease" which the treatment centres had been established to eliminate. In their view, it was both a medical and moral imperative that "this most offensive portion of the population be identified and circumscribed". ${ }^{56}$ Moreover, these were views shared by the Venereal Diseases Section of the Scottish Board of Health. ${ }^{57}$ Accordingly, as the Scottish campaign for the compulsory notification and treatment of venereal disease

${ }^{51}$ Glasgow M.O.H., annual report, 1929, p. 15.

52 Edinburgh P.H.D., annual reports.

53 See, e.g., ibid., 1921, p. xvi; 1923, p. 48.

54 See, e.g., ibid., 1926, pp. vi-vii.

55 Thus, Dr A. K. Chalmers, M.O.H. for Glasgow and an influential adviser to the Scottish Board of Health on VD policy viewed defaulters as "habitual libertines", who were "recessive towards the period of phallic worship" and who merely exploited the clinics "as a convenient aid to further promiscuity".

${ }^{56}$ Glasgow M.O.H., annual report, 1928, p. 155; 1929, p. 157; Edinburgh P.H.D., annual reports, 1921, p. 41; 1923, p. 48; 1925, p. 55.

57 See, e.g., S.R.O. H.H. 65/115/6, Minute by Dr T. F. Dewar, Aug. 1922. 
gathered momentum in the 1920s, groups of defaulters were especially targeted and their medical and sexual behaviour came to dominate the agenda of epidemiological research in the public health departments. In the process, issues of moral responsibility increasingly distracted public and expert debate away from any critical assessment of the real measure of the "social evil" in interwar Scotland. ${ }^{58}$

${ }^{58}$ There is, for example, a very striking contrast between the broad agenda of research into the "social epidemiology" of VD advocated by Dr A. K. Chalmers in his annual report as M.O.H. for Glasgow in 1923, and the relatively narrow preoccupation of subsequent research with the issue of default. For interesting parallels with the recent AIDS debate, see especially, G. Oppenheimer, 'In the eye of the storm: the epidemiological construction of AIDS' in E. Fee and D. M. Fox (eds), The burdens of history, Berkeley, University of California Press, 1988, pp. 267-92. 